\title{
High Risk HPV, HSIL and Primary Diffuse Large B Cell Lymphoma of Cervix: An Unsual Case
}

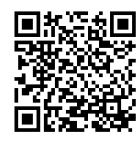

\section{Sreekala Sreehari ${ }^{1 *}$, Mohanad Diab ${ }^{2}$ and Paulina Manosalvas Martinez ${ }^{3}$}

${ }^{1}$ Department of Histopathology, NMC Royal Hospital, UAE

${ }^{2}$ Department of Medical oncology, NMC Royal Hospital, UAE

${ }^{3}$ Department of Obstetrics and Gynecology, NMC Royal Hospital, UAE

Submission: December 31, 2018; Published: January 11, 2019

*Corresponding author: Sreekala Sreehari, Department of Histopathology, NMC Royal Hospital, Khalifa City A, Abudhabi, UAE

\begin{abstract}
Primary malignant non-Hodgkin's lymphomas in the female genital tract are rare, accounting for less than $1 \%$ of all extranodal non-Hodgkin's lymphomas. HPV infection has well been documented as the causative factor for Carcinoma cervix; not malignant lymphoma of cervix. Here we report an interesting case of primary non-Hodgkin's lymphomas of uterine cervix with proven HPV 16 infection and High grade squamous intraepithelial lesion with co-existing diffuse large B-cell lymphomas (DLBCL) on histopathological examination and immunohistochemical study. The patient was successfully treated with chemotherapy after Cervical Conisation for HSIL and is now in complete remission with follow up period of 11 months. Gynecological lymphomas can be a diagnostic challenge due to nonspecific symptoms. However, when diagnosed and treated they have a good prognosis. Clinicians should therefore include lymphoma in their differential diagnosis when investigating gynecological symptoms.
\end{abstract}

\section{Case report}

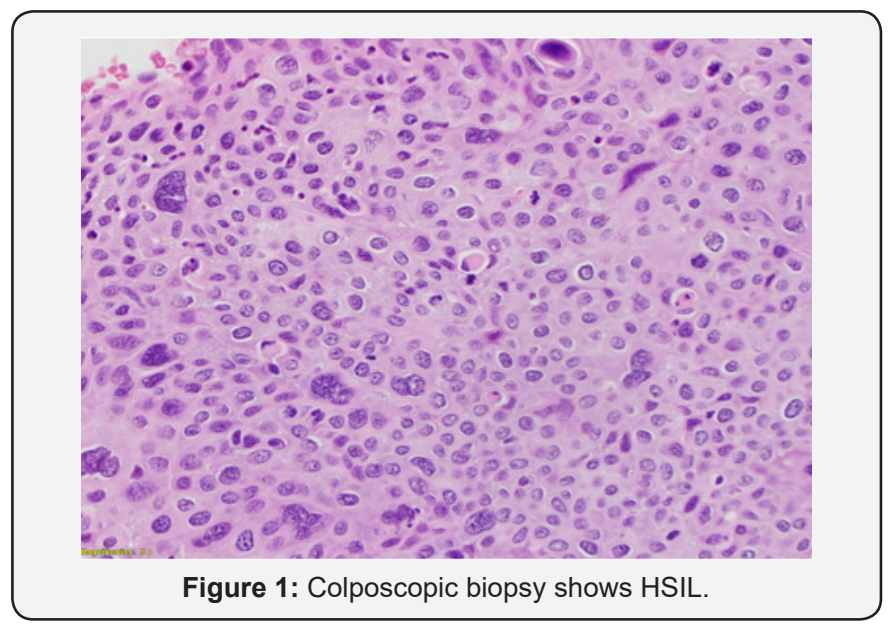

28-year-old lady went for a routine gynecological checkup where a Pap smear was taken. The report came as Low grade squamous intra-epithelial lesion (LSIL). HPV test was done; it came as positive for genotype 16 which is consistent with high risk HPV, which is a proven carcinogenic virus for cervical cancer. Colposcopic biopsy soon followed and it showed (Figure 1) High grade squamous intraepithelial lesion (HSIL) (CIN III). Cervical LEEP excision was done to cure the disease. The specimen measured $4.5 \times 3 \times 1 \mathrm{~cm}$ and was oriented at $12 \mathrm{o}^{\prime}$ clock. It was inked and serially sliced. The sections showed foci of epithelial dysplasia involving the entire thickness with loss of maturation and presence of hyperchromatic pleomorphic nuclei with involvement of the endocervical glands. The features were in keeping with High grade squamous intraepithelial lesion (HSIL) (CIN III) (Figure 2a). No histological evidence of stromal invasion was seen.

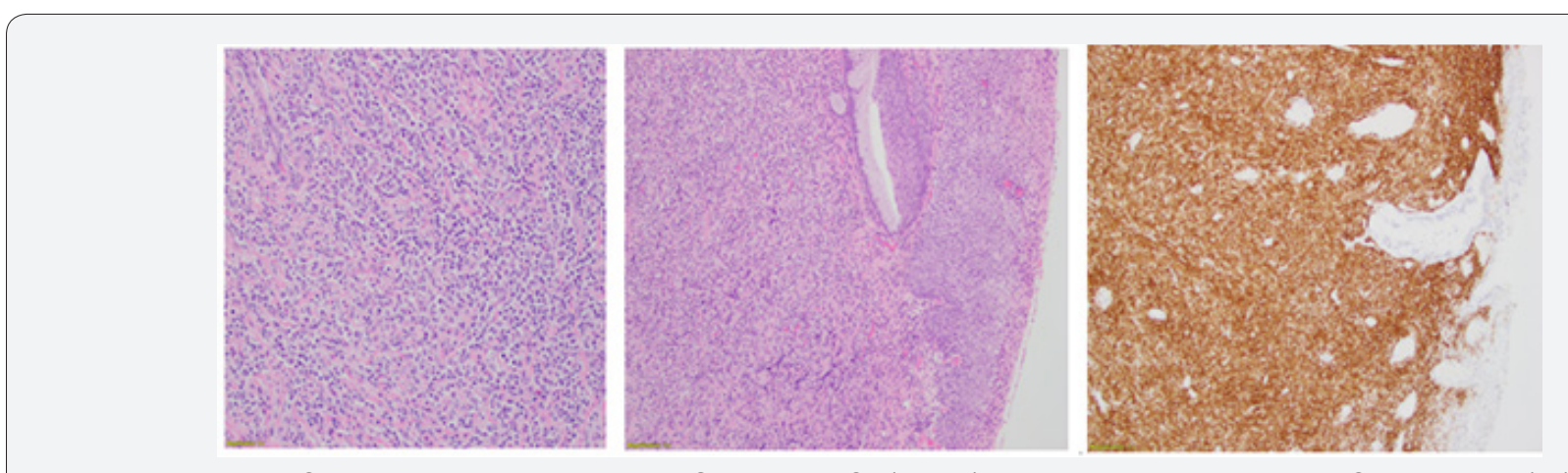

Figure 2: Cervical LEEP excision shows HSIL and DLBCL (2a, 2b) with lymphoid cells in sheets; CD20 positive (2c). 


\section{International Journal of Cell Science \& Molecular Biology}

The sub epithelial region showed (Figure 2b) sheets of neoplastic lymphoid cells with irregular nuclear contours, vesicular nuclei, occasional prominent nucleoli and moderate amount of eosinophilic cytoplasm. Mitosis was frequent. Spindling of tumour cells was evident in areas. Immunohistochemical work up showed the tumour cells were positive for CD20 (Figure 2c) while negative for CD3, CD10, Bcl-6 and Cyclin D1. The neoplasm extended up to the deep resection margin. The final diagnosis was given as High grade squamous intraepithelial lesion (HSIL) (Cervical intraepithelial Neoplasia III/ CIN III) with Non-Hodgkin's Lymphoma B-cell type; Diffuse Large B Cell (DLBCL) Further staging work up and imaging was done (Figure 3) which showed extension of neoplasm to the vaginal fornices, the anterior vaginal wall and the parametrium with involvement of the left ureteric wall and subsequent mild hydronephrosis.

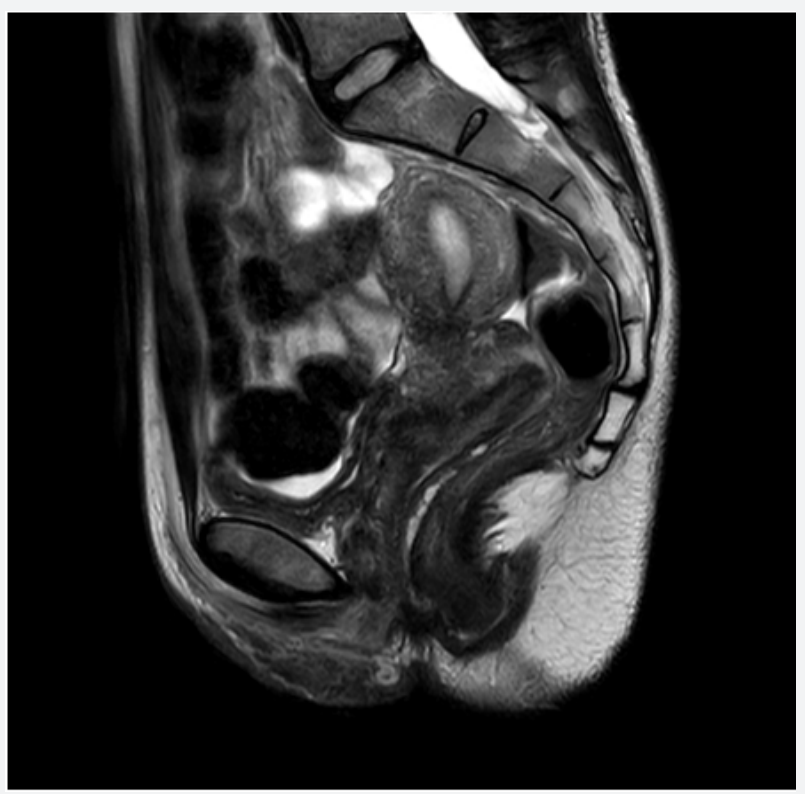

Figure 3: MRI shows extension of neoplasm to the vaginal fornices, the anterior vaginal wall and the parametrium.

CT neck, chest and abdomen showed no evidence of metastasis. In chest and abdomen; no significant abnormality noted. No significant lymphadenopathy or metastasis in chest. In abdomen, liver was displaying multiple hepatic focal lesions with progressive fill in the contrast likely hemangiomatous left hydroureteronephrosis, left ovarian cyst, retained fluid within the uterine cavity. PET CT scan impression came as hypermetabolic lesions involving the cervix with vaginal and parametrial involvement in keeping with biopsy proven metabolically active lymphoma. The remainder of the study shows no evidence of FDG avid lymphoma. Mild left hydronephrosis was noted. Since Lymphoma of cervix is a very uncommon lymphoma type and surgery has removed most of the disease, in the tumour board it was planned to consider chemotherapy followed by radiotherapy based on available data; measures that could be used in treating lymphoma of cervix. Different options of treatment was discussed and finally planned to give her 6 Cycles of R-CHOP followed by PET- CT and involved field Radiotherapy.
Since the patient was just engaged only and with no children, fertility issue had been discussed with her. Patient decided not to do any fertility preservation procedure. So prophylactic Goserelin injections to increase the chance of being fertile was also planned; once every 4th week up to 6 months after last chemotherapy. After 6 cycles of R- CHOP the patient was sent for PET- CT and impression showed a complete response to therapy. Hence a follow up PET- CT was planned after 3 months. This also showed complete response. The case was rediscussed in the tumour board and since the patient being young, unmarried and with no children and had a complete metabolic response to treatment, it was decided not to give her any Radiotherapy; but to follow up with 6 monthly PET- CT and bloods. To date 13 months after the diagnosis, she is healthy and disease free.

\section{Discussion}

Primary cervical lymphoma is rare and involvement of the cervix by a lymphoproliferative disorder is more commonly seen in the setting of systemic disease [1]. It affects adult women over a wide age range. Vaginal bleeding is the most common symptom. Lymphomas are often bulky tumours, sometimes with circumferential enlargement of the cervix ("barrel-shaped" cervix) [1,2]. Cervical diffuse large B-cell lymphomas, which is the predominant type are are often associated with prominent sclerosis and may be associated with a cord-like arrangement or spindle-shaped tumor cells ("spindle cell variant") [3]. Rare cervical marginal zone lymphomas (MALT lymphomas), Burkitt lymphomas [4] and extranodal NK/Tcell lymphomas, nasaltype, have been described. Differential diagnoses of cervical lymphomas include sarcoma, poorly differentiated carcinoma, neuroendocrine tumours, Malignant Mixed Mullerian tumour, Melanoma, extraosseous Ewing's sarcoma, and chronic cervicitis. Most cases of NHL involving uterine cervix presents at stage I or II. The optimal treatment of such tumours is not clear. These tumours have been managed with chemotherapy, [5] radiotherapy, and surgery, alone or in combination [6]. Heredia et al. demonstrate the use of combination of CHOP $\times 3$ plus involved field radiotherapy as therapy for this malignancy [7]. The association of HPV infection with cervical cancer is well known; though literature on HPV association to cervical lymphoma is scanty. A Danish study [8] noted that HPV infection is associated with an increased risk of Lymphoma. This association may be attributable to a chronic immune activation induced by persistent HPV infection and/or failure of the immune system both to clear HPV infection and to control lymphoma development.

\section{Conclusion}

In our patient the rare combination of High-risk HPV, Lymphoma and High grade squamous intraepithelial lesion was quite interesting. But the efficient interdisciplinary discussions gave her a wonderful outcome.

\section{References}

1. Vaidya S, Kapoor C, Ohri N (2013) Early invasive squamous cell carcinoma of the tongue. SRM J Res Dent Sci 4: 35-38. 
2. Algowaifly M, Alhadlaq RK (2016) Oral squamous cell carcinoma on the lateral border of the tongue: A case report. Dentistry 6: 381.

3. Rui PP, Albuquerque DDS, Richards A (2016) Squamous-cell carcinoma of the tongue. N Engl J Med 374: e32.

4. Basden GT, Celestine, Chukwuemeka, Mbaegbu (1996) The Effective Power of Music in Africa. Niger Ibos London: Frank Cass.

5. Macartney JC, Rollaston TP, Codling BW (1980) Use of a histopathology data pool for epidemiological analysis. J Clin Pathol 33(4): 351-353.

6. Lin GC, Qiu WL, Zhang ZY (2003) Relevant factors and management for patients with squamous carcinoma in tongue without clinical cervical lymphatic node metastasis. Zhonghua Kou Qiang Yi Xue Za Zhi 38(1): 5-8.

7. Zwetyenga N, Majoufre Lefebvre C, Siberchicot F (2003) Squamouscell carcinoma of the tongue: Treatment results and prognosis. Rev Stomatol Chir Maxillofac 104(1): 10-17.

This work is licensed under Creative Commons Attribution 4.0 License

DOI: 10.19080/IJCSMB.2019.05.555666
8. Jones AS, Rafferty M, Fenton JE (2007) Treatment of squamous cell carcinoma of the tongue base: Irradiation, surgery, or palliation? Ann Otol Rhinol Laryngol 116(2): 92-99.

9. Ganly I, Patel S, Shah J (2012) Early stage squamous cell carcinoma of the oral tongue Clinicopathologic features affected outcome. Cancer 118(1): 101-111.

10. Gourin CG, Johnson JT (2001) Surgical treatment of squamous cell carcinoma of the base of tongue. Head Neck 23(8): 653-660.

11. Ruiz Martin I, Garcia Recuero I, Urbanowicz M, Zubillaga Rodriguez I (2016) Spindle cell squamous carcinoma of the tongue in a child. Oral Maxillofac Surg Cases 2(4): 40-45.

\section{Your next submission with Juniper Publishers} will reach you the below assets

- Quality Editorial service

- Swift Peer Review

- Reprints availability

- E-prints Service

- Manuscript Podcast for convenient understanding

- Global attainment for your research

- Manuscript accessibility in different formats

( Pdf, E-pub, Full Text, Audio)

- Unceasing customer service

Track the below URL for one-step submission https://juniperpublishers.com/online-submission.php 